Book Review

\title{
Cultural Resiliency and the Rise of Indigenous Media
}

\author{
Derek Moscato \\ School of Journalism and Communication, University of Oregon, Eugene, OR 97405, USA; \\ E-Mail: dmoscato@uoregon.edu
}

Submitted: 5 May 2015 | Accepted: 13 July 2015 | Published: 26 April 2016

\begin{abstract}
Valerie Alia's book, The New Media Nation: Indigenous Peoples and Global Communication (New York: Berghahn Books, 2012, 270 pp.), points the way to major communication breakthroughs for traditional communities around the world, in turn fostering a more democratic media discourse. From Canada to Japan, and Australia to Mexico, this ambitious and wide-reaching work examines a broad international movement that at once protects ancient languages and customs but also communicates to audiences across countries, oceans, and political boundaries. The publication is divided roughly into five sections: The emergence of a global vision for Indigenous communities scattered around the world; government policy obstacles and opportunities; lessons from Canada, where Indigenous media efforts have been particularly dynamic; the global surge in television, radio and other technological media advances; and finally the longterm prospects and aspirations for Indigenous media. By laying out such a comprehensive groundwork for the rise of global Indigenous media over a variety of formats, particularly over the past century, Alia shows how recent social media breakthroughs such as the highly successful \#IdleNoMore movement-a sustained online protest by Canada's First Nations peoples-have been in fact inevitable. The world's Indigenous communities have leveraged media technologies to overcome geographic isolation, to foster new linkages with Indigenous populations globally, and ultimately to mitigate structural power imbalances exacerbated by non-Indigenous media and other institutions.
\end{abstract}

\section{Keywords}

communication; indigenous; first nations; globalization; native American; new media

\section{Issue}

This book review is part of the issue "The Impact of Media on Traditional Communities", edited by Raul Reis (Florida International University, USA).

(C) 2016 by the author; licensee Cogitatio (Lisbon, Portugal). This article is licensed under a Creative Commons Attribution 4.0 International License (CC BY).

With the closure of 150 remote Aboriginal communities in Western Australia imminent during the spring of 2015, including their own village of 200 residents at the edge of the Great Sandy Desert, siblings Layangali and Nelson Bieundurry needed a platform to voice their opposition to another government-forced relocation of Indigenous populations. Australia's mainstream media had proven to be mainly indifferent to their plight. Yet the pair soon found an effective venue for dissent in social media. Starting with family and friends on their Facebook accounts and then moving to the microblogging platform of Twitter, the \#SOSBlakAustralia movement came to connect Indigenous communities and their supporters not only across Australia but indeed the world (Stein, 2015).
Similarly, when Canada's \#ldleNoMore movement became a significant online force in 2012, it represented the culmination of a long trajectory of media developments impacting Canada's First Nations communities. The hashtag activism, borne of growing frustration by Indigenous peoples with the environmental and social policies of the country's federal government, revealed more than just a gap of representation and citizenship, but also a disconnect between the roles of mainstream and grassroots media in representing Indigenous histories, values, and priorities.

Like \#SOSBlakAustralia, one of the defining dimensions of the movement was its transnational character. Carried by the medium of Twitter, \#ldleNoMore quickly jumped across the Canadian border into the United 
States as an online and offline movement, and was embraced by Indigenous populations in communities as geographically disparate as Los Angeles, Minneapolis, and Buffalo. Heat maps of the social media movement also showed the hashtag's remarkable popularity globally: in Australia, Finland, Egypt, the United Kingdom, and Mexico. This was a remarkable fusing of traditional customs with new and liberating media technologies to promote a pan-Indigenous agenda and global network.

Valerie Alia's book, The New Media Nation: Indigenous Peoples and Global Communication, points the way to these more recent communication breakthroughs for traditional communities around the world. A scholar, journalist, photographer, and poet, Alia is currently Adjunct Professor at Royal Roads University in Victoria, Canada. Her New Media Nation represents a broad international movement that at once protects ancient languages and customs but also communicates to audiences across countries, oceans, and political boundaries. This necessary and timely work is divided roughly into five sections: The emergence of a global vision for Indigenous communities scattered around the world; government policy obstacles and opportunities; lessons from Canada, where Indigenous media efforts have been particularly dynamic; the global surge in television, radio and other technological media advances; and finally the long-term prospects and aspirations for Indigenous media.

The United States, we learn, presents a particularly hopeful case. Alia notes that while U.S. policies have historically vacillated between assimilationist and outright hostility (such as the tragic relocations of Indigenous communities to Oklahoma via what is known as the Trail of Tears), a cultural renaissance that started in the 1960s has given way to important institutional changes, themselves ushering in a crucially expansive era for Indigenous media and culture. Literature-nonfiction, fiction, and poetry-has thrived. News media developments have been equally prolific, though they have enjoyed mixed results in terms of their long-term viability. She points to the example of the Pulitzernominated Tundra Times, Alaska's landmark Indigenous newspaper, which ceased publication in 1997, attributed in part to declining circulation and advertising revenues. Indigenous journalism success stories are susceptible to the same downfalls as their nonIndigenous counterparts.

At the same time, Alia's work acknowledges but doesn't dwell upon the contentious arena of Indigenous representation in mainstream filmmaking, particularly Hollywood productions, something well detailed in the 2009 documentary Reel Injun directed by Cree filmmaker Neil Diamond. (The issue of Indigenous representations in Hollywood films most recently flared up in the global mainstream media when Native American actors walked off of the set of a comedy produced for the Netflix streaming service called The Ridiculous Six, the script from which depicted contentious and offensive caricatures of Native Americans.) Rather, Alia is focused on landmark cinematic works from Indigenous filmmakers-including 2000's Atanarjuat: The Fast Runner from Inuk director Zacharias Kunuk. The first full-length feature to be produced, written and acted by Inuit in Inuktitut, the movie also won the Camera d'Or award at the 2001 Cannes Film Festival.

The film's massive success underscores one of the key themes of Alia's work: the ability of Indigenous media to transcend national borders and foster international linkages. In the Americas, she points to the example of Canada's Native Journalists' Association morphing with the U.S.-based Native American Journalists' Association. Such a coming together, she argues, represents a point that Indigenous people have been making all along: "The cultural and political divisions between Indigenous people in Canada and the United States have been artificially created and manipulated by state governments." Significant also is the rate of change defining these developments. Alia, reflectively noting her own participative role in fostering Native American media projects in Washington State with the Lummi Nation, points out that in the 1990s, the focus was still very much on more localized newspapers and newsletters. A decade later, the Lummi were producing digital media, including websites, and a television newscast called Northwest Indian News-itself carried by television feeds across the northwestern United States and into Canada as well.

Within Canada, Alia points to the rise of one of that country's most important developments in Indigenous media: The Aboriginal Peoples Television Network (APTN) - the first Aboriginal national broadcaster in the world. Run and produced by Canada's First Nations, Inuit, and Métis peoples for a nationwide and multicultural Canadian audience, it follows a tradition of community engagement and participation cultivated by Indigenous radio. It has fostered national visibility and opportunity for Canada's First Nations musicians and other cultural performers, and provides distinctly Aboriginal perspectives on news and current events to coexist with Aboriginal-themed (and produced) entertainment. While over 50 percent of the programming is in English, nearly one-third takes place in traditional Aboriginal languages. Australia's emerging National Indigenous Television Service (NITV) has a similar mandate in reflecting the diversity and Aboriginal cultures and communities in the country.

However, it isn't until the fourth chapter of New Media Nation that the breadth of global Indigenous communication and its crucial societal role is laid out fully for the reader. Concrete examples of high-tech media to go along with the low-tech include solarpowered satellite receivers delivering programming from international satellite services; diesel-powered 
video screenings of a cable television project for the Tripura Adivasi people in Bangladesh, with the goal of reclaiming cultural traditions and providing information to the wider community; and the Guatemala Radio Project, broadcasting to Maya peoples across Guatemala. The importance of Guatemala's Indigenous languages being heard on community radio is juxtaposed against "Spanish-language commercial radio and television (that) leaves Maya peoples out of the picture." Across the Pacific, in Japan, Canada's flourishing Indigenous radio programs inspired the creation of FMPipaushi, which carries programming of northern Japan's Ainu people, whose culture was long suppressed by Japanese assimilation programs. Today, Pipaushi's programming has evolved into Internet transmission of Ainu-language news and culture across the Asian continent and around the world.

It's in the realm of video, however, where the possibilities of global Indigenous new media seem to be most fully realized, and documented, by Alia. In presenting Indigenous media projects from Mexico, the author invokes the important work of Amalia Córdova and Gabriela Zamorano, emphasizing the centrality of the production process in democratizing media. In tracing the development of Indigenous video in Latin America, they present such deep-rooted cultural aesthetics as "the poetics of Indigenous media" and contrast the notion of imperfect media-rooted in active audiences and subversive ideas-with the "hegemonic structures of film production, distribution, and consumption dictated by the Hollywood system" (Córdova $\&$ Zamorano, 2004). Building upon this foundation, Alia points to the formation of the Organizacion Mexicana de Videoastas Indigenas (OMVIAC) in 1992, as well as contemporary clusters of independent and statesponsored media production centers across Mexico. One such example comes from Chiapas, where the Chiapas Media Project-producing a number of videos, including The Land Belongs to Those Who Work It, about a dispute between local communities and resort developers-positions itself as part of the resistance as opposed to merely documenting it.

Identity politics are pivotal, but Alia points out they can also can come with their own risks. In the U.S., she highlights a case from 2007, when the Cherokee Nation voted to revoke the 2,800 descendants of former slaves "owned" by Cherokee people of their tribal citizenship. It's a clear example of her warning that "communities that are already marginalized sometimes promote the marginalization of others" - but also to identity politics being exploited to further the aim of existing divide-and-conquer tactics deployed by governments in order to reassign land holdings.

For a book as ambitious and wide-reaching as this one is, New Media Nation is not without its limitations. There is a greater depth of analysis for media developments in the Americas than Asia, for example. This is a minor quibble, however, as providing the same degree of texture to each international case examined would probably require at least another volume on this topic. At the same time, Alia is wisely playing to her strengths. At the same time, she makes up for any national gaps by drawing from her rich sources, primary research, and key scholarship from international and Indigenous communication.

Where Alia's book really shines is in its ability to understand various Indigenous media on the terms of Indigenous communities, and its mapping out of connections to Indigenous audiences worldwide to create transformative moments and movements. Building on Córdova and Zamorano for example, the point of "imperfect video" and other grassroots communication is not of high production value for a mass audience. It is instead about cultivating communicative participation, media democracy, and cultural tradition. Writing toward a theory of cultural resiliency and drawing from the metaphor of a medical awakening, she postulates that the "cultural coma" once afflicting Indigenous communities may be easier to recover from than initially thought: "Just as a person in a coma may appear to be dormant, but often has consciousness, people experiencing various stages of cultural coma may also retain consciousness. Cultures are never static." The New Media Nation is explained as part of a rapidly growing global media movement-one that both facilitates interventions into existing media and provides a platform for local and regional minority voices to become "global choruses."

Despite many advances, there continues to be a shaky relationship between dominant media forms and Indigenous communities. As Alia notes, media depictions of Indigenous peoples continue to be steeped in the language of conquest and colonization, often treating them as "exotic items for study or observation" when they are not being relegated to historical footnote status. Recent controversies involving Indigenous depictions in popular culture underpin this idea-from the aforementioned Ridiculous Six film production to the controversial Redskins mascot adorning the jersey of Washington, D.C.'s National Football League team. Indigenous media networks, meanwhile, exist in spite of insurmountable obstacles-which can come to include hostile state governments, threatened corporations, and other forms of opposition. Both journalists and Indigenous leaders have been targeted by authoritarian governments globally. Public reaction to such initiatives can range from supportive to indifferent to antagonistic. Alia remains hopeful, however. The upsides of such adventures into global media completely override the bumps along the journey: "The New Media Nation is a catalyst for identity association and transformation, a multidimensional international movement, and a force for global change."

But what of the development of social media in In- 
digenous communication? Canada's \#ldleNoMore movement on Twitter proved to be not only a cultural force but also a political one-moving ideas and activism across borders, but also into mainstream media and politics. The Indian Country Today digital media network continues to set an Indigenous agenda in North America for issues ranging from the Keystone XL pipeline environmental debate to the battle for gay marriage on tribal lands. Its YouTube channel's video of Native American actors bravely walking off the set of Ridiculous Six has been championed and rebroadcast by mainstream entertainment programs like $T M Z$. Such digital media channels-and some of the transformative media moments they have created-are not a focus of this book, nor are they meant to be. But by laying out such a comprehensive groundwork for the rise of global Indigenous media over a variety of forms, particularly over the past century, Alia shows how these recent social media breakthroughs were in fact inevitable. The world's Indigenous communities have leveraged media technologies to overcome geographic isolation and ultimately mitigate structural power imbalances exacerbated by non-Indigenous media.
From radio to satellite and now to Twitter, Aboriginal communication continues to build communities, foster dialogue, transcend borders, and reclaim cultures - in the process creating an unprecedented global nation.

\section{Conflict of Interests}

The author declares no conflict of interests.

\section{References}

Córdova, A., \& Zamorano, G. (2004). Mapping Mexican media: indigenous and community video and radio. Native Networks. Smithsonian National Museum of the American Indian. Retrieved from http://nmai. si.edu/explore/film-media/native-media-topics

Stein, G. (2015, April 30). Family harnesses social media to protest against community closures. $A B C$ News Online. Retrieved from http://www.abc.net.au/ news/2015-04-30/protest-against-forced-closureaboriginal-communities/6431558/mappingmexican-media

\section{About the Author}

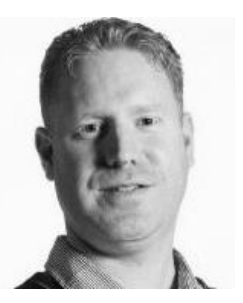

\section{Derek Moscato}

Derek Moscato is a PhD student in the Media Studies program at the University of Oregon's School of Journalism and Communication. His research interests include environmental communication, globalization, and strategic communication. His work also addresses activism, the communication of resources extraction, corporate social responsibility, and public diplomacy. 